\title{
Non-oncology physician visits after diagnosis of cancer in children
}

\author{
Marianne J. Heins ${ }^{*}$, Maria F. Lorenzi ${ }^{2}$, Joke C. Korevaar ${ }^{1}$ and Mary L. McBride ${ }^{2}$
}

\begin{abstract}
Background: Children diagnosed with cancer often require extensive care for medical, psychosocial and educational problems during and after therapy. Part of this care is provided by family physicians and non-cancer specialists, but their involvement in the first years after diagnosis has barely been studied. Studying non-oncology physician visits may provide insight into the roles of different health care providers.

Methods: We included 757 children diagnosed with cancer under age 15 between 1991 and 2001 from a Canadian provincial registry, and matched each to 10 controls of the same birth year and sex. We determined the number of family physician and non-cancer specialist visits in the 5 years after diagnosis (for patients) or inclusion (for controls) using data from the provincial health insurance plan.

Results: In the first year after diagnosis, almost all patients visited both a family physician and non-cancer specialist. Although after 5 years percentages decreased to 85 and $76 \%$, respectively, these were still significantly higher than in controls. In the first year after diagnosis, both family physicians and non-cancer specialists were often consulted for neoplasms (62 and $90 \%$, respectively) and to discuss results of lab tests. In addition, family physicians were often consulted for general symptoms and non-cancer specialists for nervous system problems and complications of medical care.
\end{abstract}

Conclusions: Family physicians and non-cancer specialists are highly involved in the care for children with cancer in the first years after diagnosis, including for health problems related to cancer or its treatment. This necessitates good communication among all physicians.

Keywords: Neoplasms, Child, Primary health care, Leukemia, Lymphoma, Child health services

\section{Background}

Survival rates of children diagnosed with cancer have improved greatly in the last 50 years, from $30 \%$ surviving more than 5 years in the 1960s up to more than $80 \%$ currently $[1,2]$. As more and more children survive, it is also increasingly being realized that survival comes at a price; children who survive cancer often experience long-term health problems, related to the cancer itself or its treatment $[3,4]$. Common problems are neurocognitive dysfunction, cardiovascular diseases, infertility or gonadal dysfunction, and psychosocial problems [5].

Especially in the first years after diagnosis, children require extensive care for medical, psychosocial and educational problems. Many health care providers may be

\footnotetext{
*Correspondence: m.heins@nivel.nl

${ }^{1}$ Netherlands Institute for Health Services Research (NIVEL), P.O Box 15683500 BN Utrecht, The Netherlands

Full list of author information is available at the end of the article
}

involved in this care. Treatment for childhood cancer is relatively lengthy and patients are often closely monitored by a cancer specialist for several years after the diagnosis, but they may also visit a non-cancer specialist or a family physician for the more general health effects they experience because of the cancer and its treatment, such as problems with growth and development and learning [6].

In many countries, the family physician has an important role in the long-term care for cancer survivors. The generalist and patient-focused view of the family physician facilitates addressing the variety of issues that these patients encounter. The role of the family physician has mostly been studied among adult cancer patients and several studies showed that up to 10 years after diagnosis they visit their family physician more often than noncancer controls of the same age [7, 8]. Increased family 
physician visits are also seen in adult survivors of childhood cancer [9-11].

Non-oncology physician visits in the first few years after diagnosis of cancer in children have barely been studied. We therefore do not know which roles the noncancer specialist and family physician play in the care for these children during this period; how often are they visited and for which health problems. If family physicians and non-cancer specialists are also involved in care for cancer-related problems, this may benefit continuity of care towards long-term follow-up but it also necessitates good communication between all health providers involved.

Using the linked provincial registry, clinical, and administrative datasets of the Childhood, Adolescent, and Young Adult Cancer Survivor (CAYACS) Research Program, [12] we aimed to compare non-oncology physician visits in the first 5 years after diagnosis of childhood cancer to that of non-cancer controls of the same age and sex. We looked at both the number of visits and the reasons for these visits.

\section{Methods}

\section{Study population}

Patients were selected from the British Columbia (BC) cancer registry. Inclusion criteria were diagnosis with a primary cancer before 15 years of age in the period 1991 until 2001, residence in the province of BC at time of diagnosis and successful linkage to registration files from the provincial health insurance plan based on a unique Personal Health Number. For each patient ten control children of the same birth year and sex were selected from the provincial health insurance plan registry.

\section{Data collection}

Data on non-oncology physician visits of both patients and controls were retrieved from the provincial health insurance plan, containing records of all medicallynecessary physician-ordered outpatient services of residents of BC since 1986 (British Columbia Ministry of Health [Mc Bride] (2013): Medical Services Plan (MSP) Payment Information File. Population Data BC BC Cancer Agency. Data Extract. MOH (2012). http://www.popdata.bc.ca/data). Diagnoses were coded using the ICD (International Classification of Diseases) [13]. Available data on family physician and specialist visits and diagnoses made during these visits were extracted from diagnosis (for patients) or inclusion (for controls; individually matched to case diagnosis date) up to 5 years after this date. Data were right-censored if children died or they moved out of BC. Clinical data of patients (i.e. diagnosis, treatment, relapse status) was available as part of the CAYACS Program [12] Residence of both patients and controls, recorded as annual postal code, was retrieved from the provincial health insurance plan (BC Vital Statistics Agency [McBride] (2012): Vital Statistics Deaths. Population Data BC BC Cancer Agency. Data Extract BC Vital Statistics Agency (2012). http://www.popdata.bc.ca/data), and used to link to census data to generate area-specific socioeconomic status, region (i.e. regional health administration area) and urban or rural.

\section{Analysis}

First, we compared the percentage with a family physician and non-cancer specialist visit in cancer patients and controls in each year using a $X^{2}$ test. We then calculated the mean number of family physician and noncancer specialist visits in those cancer patients and controls with a visit. We then used multiple negative binomial regression analyses to test whether the difference between both groups was statistically significant [14]. We chose this type of regression analysis since our outcome variable, the number of visits, is a count variable and follows a so-called negative-binomial distribution. We tested for overdispersion in the data, which was indeed present. Negative binomial regression is especially suited for this type of distribution. For each year after diagnosis or inclusion we built a model with the number of visits as dependent, and patient/ control status as independent variable.

Next, we examined the reasons that had been recorded for each visit, by calculating the percentage of patients and controls with a visit by ICD chapter. Finally, we calculated the percentage of patients and controls with a visit by specialty.

Analyses were performed using $\mathrm{IBM}^{\bullet} \mathrm{SPSS}^{\bullet}$ version 21. A p-value below 0.05 was considered statistically significant.

\section{Results}

The BC Cancer Registry identified 757 children under 15 years of age diagnosed with cancer between January 1991 and December 2001. They were matched to 7441 controls of the same birth year and sex. Half of the patients were under 4 years of age, and $56 \%$ were males. Patients and controls did not differ significantly on any baseline characteristics (See Table 1). Clinical characteristics of the cancer patients are presented in Table 2 . Most frequent cancer types were leukemia and central nervous system tumours and $71 \%$ of the patients had been treated with chemotherapy.

In the first year after diagnosis almost all cancer patients visited a family physician (97\%) and non-cancer specialist (98\%, see Table 3). This was significantly more than the controls, of whom $83 \%$ visited a family physician and only $29 \%$ a non-cancer specialist. In the years thereafter, the proportion of cancer patients with a visit declined steadily to $85 \%$ for family physician and to 
Table 1 Socio-demographic characteristics of patients and controls

\begin{tabular}{|c|c|c|c|c|c|c|}
\hline & & \multicolumn{2}{|c|}{ Patients $(N=757)$} & \multicolumn{2}{|c|}{ Controls $(N=7441)$} & \multirow[t]{2}{*}{$p$} \\
\hline & & $n$ & $\%$ & $n$ & $\%$ & \\
\hline \multirow[t]{2}{*}{ Sex } & Male & 421 & 56 & 4096 & 55 & .77 \\
\hline & Female & 336 & 44 & 3345 & 45 & \\
\hline \multirow[t]{3}{*}{ Age at diagnosis/inclusion } & $0-4$ & 358 & 47 & 3521 & 47 & 1.00 \\
\hline & $5-9$ & 196 & 26 & 1935 & 26 & \\
\hline & $10-14$ & 203 & 27 & 1985 & 27 & \\
\hline \multirow[t]{6}{*}{ Socioeconomic Status Quintile (SES) } & 5 (highest) & 142 & 20 & 1306 & 18 & .31 \\
\hline & 4 & 139 & 18 & 1401 & 19 & \\
\hline & 3 & 162 & 21 & 1409 & 19 & \\
\hline & 2 & 143 & 19 & 1462 & 20 & \\
\hline & 1 (lowest) & 129 & 17 & 1432 & 20 & \\
\hline & Unknown & 42 & 6 & 345 & 18 & \\
\hline \multirow[t]{5}{*}{ Urban/rural Status } & Metropolitan & 400 & 52 & 4104 & 56 & .37 \\
\hline & Large Community & 82 & 11 & 747 & 10 & \\
\hline & Small Community & 148 & 20 & 1283 & 18 & \\
\hline & Rural & 126 & 17 & 1199 & 16 & \\
\hline & Unknown & 0 & 0 & 1 & 0 & \\
\hline \multirow[t]{6}{*}{ Region of Residence } & Interior & 127 & 17 & 1184 & 16 & .86 \\
\hline & Frasier & 244 & 32 & 2469 & 34 & \\
\hline & Vancouver Coastal & 166 & 22 & 1645 & 22 & \\
\hline & Vancouver Island & 123 & 16 & 1219 & 17 & \\
\hline & Northern & 81 & 11 & 692 & 9 & \\
\hline & Unknown & 16 & 2 & 146 & 2 & \\
\hline
\end{tabular}

Table 2 Clinical characteristics of patients $(N=757)$

\begin{tabular}{|c|c|c|c|}
\hline & & Number & Percent \\
\hline \multirow[t]{2}{*}{ Calendar period of diagnosis } & 1991-1995 & 410 & 54 \\
\hline & 1996-2000 & 347 & 46 \\
\hline \multirow[t]{8}{*}{ Diagnosis } & Leukemia & 263 & 35 \\
\hline & Central Nervous System & 153 & 20 \\
\hline & Lymphoma & 78 & 10 \\
\hline & Soft tissue sarcoma & 46 & 6 \\
\hline & Bone & 33 & 4 \\
\hline & Germ Cell & 32 & 4 \\
\hline & Carcinoma & 24 & 3 \\
\hline & Other & 128 & 17 \\
\hline \multirow[t]{5}{*}{ Treatment Modality } & Surgery only & 165 & 22 \\
\hline & Chemotherapy (Chemo) & 402 & 53 \\
\hline & Radiation (RT) & 22 & 3 \\
\hline & Chemo and RT & 136 & 18 \\
\hline & Other/Unknown & 32 & 4 \\
\hline \multirow[t]{2}{*}{ Relapse status at end follow-up } & Cancer free & 678 & 90 \\
\hline & Relapse/secondary cancer & 79 & 10 \\
\hline
\end{tabular}


Table 3 Proportion of patients and controls with at least one physician visit, and mean (SD) number of visits of those with a visit by time since diagnosis

\begin{tabular}{|c|c|c|c|c|c|c|c|c|c|c|c|c|c|c|c|c|c|}
\hline \multirow[t]{2}{*}{ Visits } & & \multicolumn{3}{|l|}{ Yr. 1} & \multicolumn{3}{|l|}{ Yr2 } & \multicolumn{3}{|l|}{ Yr3 } & \multicolumn{3}{|l|}{ Yr4 } & \multicolumn{3}{|l|}{ Yr5 } & \multirow[t]{2}{*}{ p-trend } \\
\hline & & $\mathrm{N}$ & $\%$ & No. Visits & N & $\%$ & No. Visits & $\mathrm{N}$ & $\%$ & No. Visits & N & $\%$ & No. Visits & $\mathrm{N}$ & $\%$ & No. Visits & \\
\hline \multirow[t]{2}{*}{ All visits } & Patients & 756 & $100^{a}$ & $29.9(18.5)^{a}$ & 735 & $98^{\mathrm{a}}$ & $15.0(13.9)^{a}$ & 722 & $97^{a}$ & $12.1(10.9)^{a}$ & 709 & $96^{a}$ & $9.7(8.9)^{a}$ & 692 & $94^{a}$ & $8.4(8.0)^{a}$ & $<.001$ \\
\hline & Controls & 6290 & 85 & $5.8(5.4)$ & 6182 & 84 & $5.3(4.7)$ & 5982 & 82 & $5.0(4.5)$ & 5889 & 81 & $4.9(4.8)$ & 5763 & 80 & $4.7(4.8)$ & $<.001$ \\
\hline \multirow{2}{*}{$\begin{array}{l}\text { Family } \\
\text { physician }\end{array}$} & Patients & 737 & $97^{a}$ & $10.1(9.9)^{\mathrm{a}}$ & 683 & $91^{a}$ & $7.7(9.2)^{a}$ & 671 & $90^{\mathrm{a}}$ & $6.8(7.2)^{a}$ & 668 & $91^{a}$ & $5.4(4.8)^{a}$ & 624 & $85^{a}$ & $5.0(4.5)^{\mathrm{a}}$ & $<.001$ \\
\hline & Controls & 6143 & 83 & $5.0(4.4)$ & 6029 & 82 & $4.5(3.8)$ & 5824 & 79 & $4.2(3.6)$ & 5712 & 79 & $4.2(3.9)$ & 1720 & 78 & $4.0(3.7)$ & $<.001$ \\
\hline Non-cancer & Patients & 739 & $98^{\mathrm{a}}$ & $20.4(16.2)^{a}$ & 658 & $88^{a}$ & $8.7(10.8)^{a}$ & 619 & $83^{a}$ & $6.7(8.1)^{a}$ & 578 & $78^{a}$ & $5.6(7.5)^{a}$ & 557 & $76^{a}$ & $4.8(6.2)^{a}$ & $<.001$ \\
\hline specialist & Controls & 2158 & 29 & $2.8(3.4)$ & 2051 & 28 & $2.7(3.1)$ & 2014 & 28 & $2.7(2.8)$ & 1918 & 26 & $2.7(3.1)$ & 1866 & 26 & $2.7(3.8)$ & $<.001$ \\
\hline
\end{tabular}

No. visits is the mean number (standard deviation) of visits of those who had at least one visit

${ }^{a}$ All comparisons between patients and controls are statistically significant $(p<0.001)$

$76 \%$ for non-cancer specialist visits, which was still significantly more than the controls. If children had a visit, the number of visits was also higher in cancer patients, with a mean of 10 family physician and 20 non-cancer specialist visits in the first year after diagnosis, compared to 2 and 5 in controls, respectively. The number of visits in cancer patients dropped to about 5 family physician and 5 non-cancer specialist visits in the fifth year after diagnosis, which was still significantly higher than the controls.

In the first year 'neoplasms' and 'signs and symptoms' were the most common reason for cancer patients to visit a family physician (See Fig. 1). 'Signs \& symptoms' were for a large part 'general symptoms' (31 \%), or were related to the head and neck (11\%) or skin (10\%) (See Table 4). In the fifth year after diagnosis, visits for neoplasms had decreased, but 'signs \& symptoms' remained the most frequent reason for visit and were still significantly more frequent than in the controls (50\% versus $44 \%, p<0.001)$. Another common reason for a family physician visit for cancer patients were respiratory problems, mainly acute respiratory infections, although these were even more common in controls in the first year after diagnosis ( $41 \%$ versus $48 \%, p=0.001$ ). Other common reasons for visit were neurological problems, mainly otitis media (52\% of neurological problems), and 'additional codes', mostly visits to discuss results of laboratory tests ( $74 \%$ of additional codes).

As to non-cancer specialist visits, the most common reasons for visit were 'neoplasms' and 'additional codes', the latter mainly related to discussing results of laboratory tests (83\% of additional codes) and ear tests (13\%) (See Table 5). Although both decreased, they were still the most common reasons for visit in the fifth year after diagnosis (See Fig. 2). Another common reason for visit were 'signs and symptoms', related to a variety of health problems, such as 'general symptoms' (19\%), respiratory problems (15\%), or fever of unknown origin (10\%). Visits related to the nervous system most frequently concerned disorders of the brain (12\%) and otitis media (15\%). Finally, visits for 'Injury and poisoning' were common in the first year after diagnosis, largely related to complications of medical care (56\%). Among controls, non-cancer specialist visits were significantly less

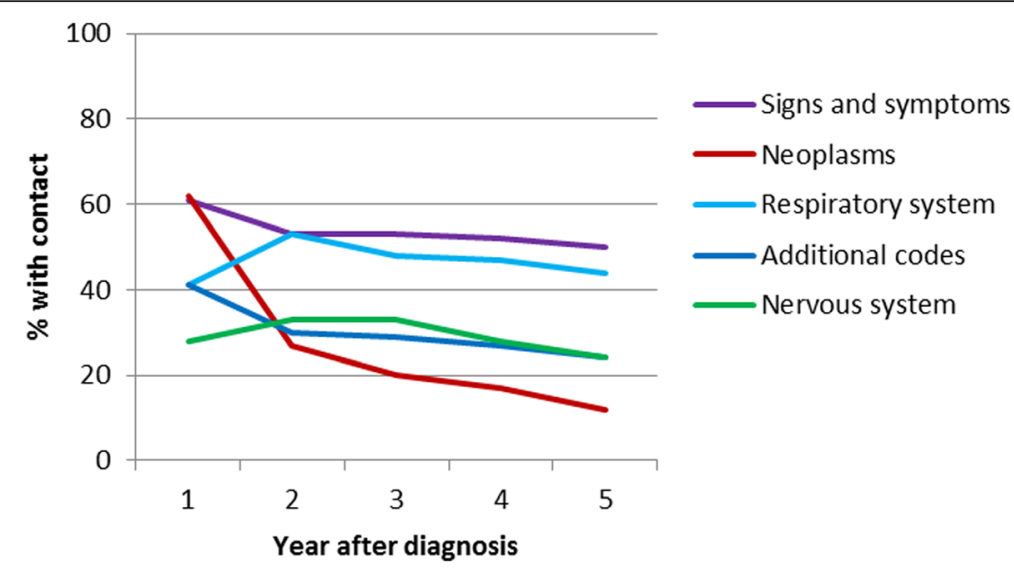

Fig. 1 Proportion of patients with a family physician visit, by reason for visit (5 most frequent) 
Table 4 Most frequent ICD codes by chapter for patients' family physician visits

\begin{tabular}{|c|c|c|c|}
\hline Chapter & ICD code & Number & Percent \\
\hline \multirow[t]{5}{*}{ Signs \& symptoms } & General symptoms & 1667 & 31.2 \\
\hline & Symptoms involving head and neck & 601 & 11.2 \\
\hline & Symptoms involving skin and other integumentary tissue & 578 & 10.8 \\
\hline & Symptoms involving respiratory system & 493 & 9.2 \\
\hline & Symptoms involving nervous and musculoskeletal systems & 465 & 8.7 \\
\hline \multirow[t]{5}{*}{ Respiratory system } & Acute upper respiratory infections of multiple or unspecified site & 1095 & 26.5 \\
\hline & Acute nasopharyngitis (common cold) & 769 & 18.6 \\
\hline & Acute pharyngitis & 429 & 10.4 \\
\hline & Acute bronchitis and bronchiolitis & 379 & 9.2 \\
\hline & Acute tonsillitis & 273 & 6.6 \\
\hline \multirow[t]{5}{*}{ Additional codes } & Laboratory & 4925 & 73.7 \\
\hline & X-Ray & 439 & 6.6 \\
\hline & Abdominal pain & 165 & 2.5 \\
\hline & Injection - Other & 150 & 2.2 \\
\hline & Plantar warts & 145 & 2.2 \\
\hline \multirow[t]{5}{*}{ Nervous system } & Suppurative and unspecified otitis media & 899 & 43.5 \\
\hline & Disorders of the conjunctiva & 182 & 8.8 \\
\hline & Nonsuppurative otitis media and eustachian tube disorders & 169 & 8.2 \\
\hline & Disorders of external ear & 131 & 6.3 \\
\hline & Other disorders of ear & 128 & 6.2 \\
\hline
\end{tabular}

Table 5 Most frequent ICD codes by chapter for patients' non-cancer specialist visits

\begin{tabular}{|c|c|c|c|}
\hline Chapter & ICD code & Number & Percent \\
\hline \multirow[t]{5}{*}{ Signs \& symptoms } & General symptoms & 510 & 19.0 \\
\hline & Symptoms involving respiratory system & 394 & 14.7 \\
\hline & Pyrexia of unknown origin & 274 & 10.2 \\
\hline & Other nonspecific abnormal findings & 173 & 6.4 \\
\hline & Symptoms involving nervous and musculoskeletal systems & 147 & 5.5 \\
\hline \multirow[t]{5}{*}{ Additional codes } & Laboratory & 12843 & 82.8 \\
\hline & Ear tests & 1961 & 12.6 \\
\hline & X-Ray & 268 & 1.7 \\
\hline & Eye tests & 131 & .8 \\
\hline & Abdominal pain & 127 & .8 \\
\hline \multirow[t]{5}{*}{ Nervous system } & Other conditions of brain & 383 & 12.2 \\
\hline & Nonsuppurative otitis media and eustachian tube disorders & 286 & 9.1 \\
\hline & Strabismus and other disorders of binocular eye movements & 286 & 9.1 \\
\hline & Epilepsy & 246 & 7.8 \\
\hline & Suppurative and unspecified otitis media & 179 & 5.7 \\
\hline \multirow[t]{5}{*}{ Injuries \& poisoning } & Other complications of procedures, not elsewhere classified & 437 & 38.5 \\
\hline & Complications peculiar to certain specified procedures & 107 & 9.4 \\
\hline & Complications of medical care, not elsewhere classified & 96 & 8.5 \\
\hline & Fracture of radius and ulna & 44 & 3.9 \\
\hline & Fracture of tibia and fibula & 40 & 3.5 \\
\hline
\end{tabular}




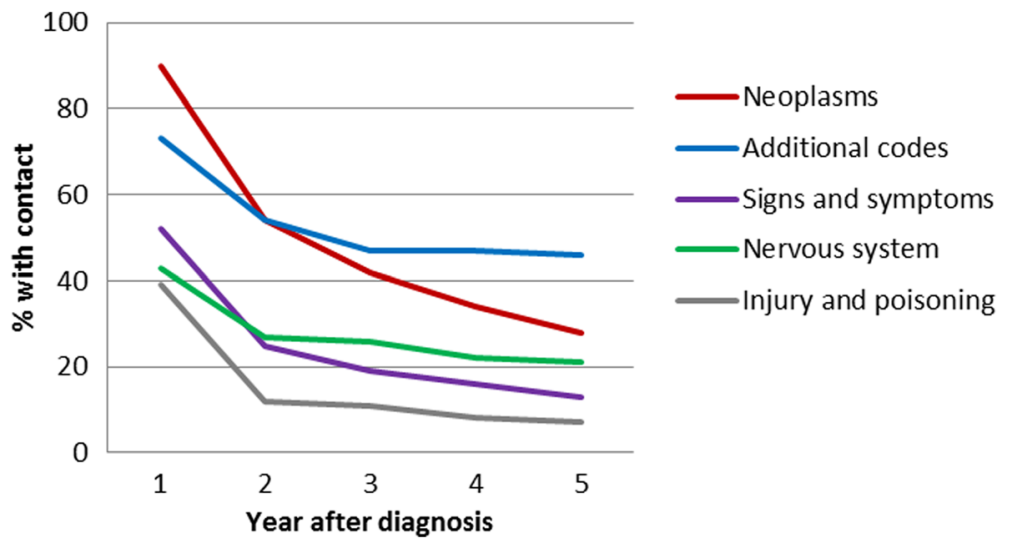

Fig. 2 Proportion of patients with a non-cancer specialist visit, by reason for visit (5 most frequent)

common; percentages of controls having a visit in any year did not exceed $8 \%$.

Paediatrics was the most frequently visited specialty provider, among both patients and controls. Eightyseven percent of the patients had a visit with a paediatrician in the first year after diagnosis, decreasing to $46 \%$ in the fifth year. This was significantly higher than the $13 \%$ among controls. Especially in the first year after diagnosis, visits to general surgery and paediatric cardiology were also common (63\% and $52 \%$, respectively). Less than $1 \%$ of the controls paid a visit to these two specialty medical providers.

\section{Discussion}

Results of this study show that children with cancer are seen very frequently by family physicians and noncancer specialists in the first years after diagnosis. The number of visits decreases gradually over the first 5 years, but remains higher than that of their peers without cancer. Both family physicians and non-cancer specialists were often consulted for neoplasm-related health problems and discussion of results of lab tests. In addition, family physicians were often consulted for general symptoms, while non-cancer specialists were more often consulted for problems to the nervous system and complications of medical care. So both family physicians and non-cancer specialists seem to be extensively involved in the care for children with cancer during this phase of care.

Physician visits in the first years after diagnosis of cancer in children have not been extensively studied. Some studies did examine physician visits after this period. Shaw et al., who surveyed physician visits in Canadian survivors of child and adolescent cancer more than 5 years after diagnosis, reported that 71 and $68 \%$ of survivors visited a family physician or a specialist in a 1-year period [11]. This is lower than the 85 and $76 \%$ we found in the fifth year after diagnosis. The CAYACS Program, using administrative health records, reported that $97 \%$ of an earlier cohort of BC childhood cancer survivors surviving more than 5 years after diagnosis saw a physician (other than an oncologist) in an outpatient setting in a 3year period [9]. The Childhood Cancer Survivor Study, surveying a cohort of survivors of child and adolescent cancer patients residing mainly in the US, found that $88 \%$ of 18-19 year olds reported a general medical contact in a two year period, more than 5 years after diagnosis [10]. However, these percentages cannot be compared to those found in this paper, as their time after diagnosis was much longer and some of them did not calculate annual but two or three yearly contact rates.

For this study we used clinical data from a large cohort of geographically-identified children with cancer linked to provincial health claims data. This enabled us to study physician visits of a large representative group of children over several years without the potential for biases associated with incomplete ascertainment and self-report, such as recall bias and selfselection. Moreover, these claims data most likely give a complete picture of the non-oncology physician visits of these children, given that all medically necessary care is provided only through the provincial government. Our data were restricted to the province of British Columbia, so some patients were lost to follow-up as they moved out of $\mathrm{BC}$; but this number is small and is unlikely to significantly alter the results [12].

Physicians could only record one ICD code per visit, although patients may have presented more than one health problem. We may therefore have missed some health problems, but physicians will likely have chosen the most important one. Unfortunately, in a 
relatively high percentage of family physician visits the related ICD code was 'general symptoms' (17 \%), which is not very informative. Although there may have been errors or lack of specificity in the diagnostic codes, it is not likely that coding errors will be different between patients and controls or between family physicians and specialists. The percentage of visit records with a missing ICD code was low $(0.2 \%)$, which indicates good data quality.

In our data, we could not make a distinction between community paediatricians and specialist paediatricians and considered both as specialist paediatricians. Community paediatricians often serve as primary care providers of children, but they have extensive training in paediatric medicine, so they could be considered somewhere between a family physician and a specialist paediatrician.

\section{Conclusions}

We found that children with cancer visited both their family physician and paediatrician very often in the first 5 years after diagnosis, also for cancer-related health problems. Although visits to both disciplines decreased somewhat over time, they are considerably more frequent than among controls during the 5-year period. The involvement of family physicians and non-cancer specialists in the care for children with cancer stresses the importance of good communication between all physicians involved in addressing health problems and treatment of the child.

\section{Abbreviations}

BC, British Columbia; CAYACS, Childhood, Adolescent, and Young Adult Cancer Survivor; ICD, international classification of diseases

\section{Funding}

MM received funding from the Canadian Cancer Society Research Institute (no. 16000 and 16001) and MH received funding from the Dutch cancer society (KWF Kankerbestrijding). The funders had no role in the design of the study, the collection, analysis, and interpretation of data or in the writing of the manuscript.

\section{Availability of data and materials}

Data will not be shared as the Ministry of Health restricts data access to the study team to protect patient confidentiality.

\section{Authors' contributions \\ $\mathrm{MH}$ participated in the design of the study, performed the statistical analysis and drafted the manuscript. ML prepared the data and helped with statistical analysis. JK participated in the design of the study and helped drafting the manuscript. MM participated in the design of the study, coordinated the study and data collection and helped to draft the manuscript. All authors read and approved the final manuscript.}

\section{Competing interests}

The authors declare that they have no competing interests.

\section{Ethics (and consent to participate)}

The study was carried out according to the precepts of the Helsinki Declaration, the Canadian Tri-Council Policy on Ethical Conduct for Research Involving Humans (TCPS), and British Columbia privacy legislation. BC Cancer Agency (BCCA) and BC Children's Hospital (BCCH) clinical Research Ethics Boards, both part of the University of British Columbia Research Ethics Board, approved of the study and waived the need for consent based on TCPS policy. BC Cancer Agency, BC Children's Hospital and BC Ministry of Health approved access to and use of the data, facilitated by Population Data BC, for this study. To protect patient confidentiality, the Ministry of Health required suppression of cells with fewer than 5 patients in the text and tables.

\section{Author details}

${ }^{1}$ Netherlands Institute for Health Services Research (NIVEL), P.O Box 15683500 BN Utrecht, The Netherlands. ${ }^{2}$ BC Cancer Research Centre, BC Cancer Agency, Vancouver, Canada.

Received: 14 September 2015 Accepted: 20 May 2016

Published online: 01 June 2016

\section{References}

1. Robison LL, Armstrong GT, Boice JD, Chow EJ, Davies SM, Donaldson SS, Green DM, Hammond S, Meadows AT, Mertens AC, et al. The Childhood Cancer Survivor Study: a National Cancer Institute-supported resource for outcome and intervention research. J Clin Oncol. 2009;27(14):2308-18.

2. Steliarova-Foucher E, Stiller C, Kaatsch P, Berrino F, Coebergh JW, Lacour B, Parkin M. Geographical patterns and time trends of cancer incidence and survival among children and adolescents in Europe since the 1970s (the ACCISproject): an epidemiological study. Lancet. 2004;364(9451):2097-105.

3. Geenen MM, Cardous-Ubbink MC, Kremer LC, van den Bos C, van der Pal HJ, Heinen RC, Jaspers MW, Koning CC, Oldenburger F, Langeveld NE, et al. Medical assessment of adverse health outcomes in long-term survivors of childhood cancer. JAMA. 2007;297(24):2705-15.

4. Oeffinger KC, Mertens AC, Sklar CA, Kawashima T, Hudson MM, Meadows AT, Friedman DL, Marina N, Hobbie W, Kadan-Lottick NS, et al. Chronic health conditions in adult survivors of childhood cancer. N Engl J Med. 2006:355(15):1572-82.

5. Oeffinger KC, Nathan PC, Kremer LC. Challenges after curative treatment for childhood cancer and long-term follow up of survivors. Hematol Oncol Clin North Am. 2010;24(1):129-49.

6. Kurt BA, Armstrong GT, Cash DK, Krasin MJ, Morris EB, Spunt SL, Robison LL, Hudson MM. Primary care management of the childhood cancer survivor. J Pediatr. 2008;152(4):458-66.

7. Heins $M$, Schellevis F, Rijken M, van der Hoek L, Korevaar J. Determinants of increased primary health care use in cancer survivors. J Clin Oncol. 2012; 30(33):4155-60.

8. Khan NF, Watson E, Rose PW. Primary care consultation behaviours of longterm, adult survivors of cancer in the UK. Br J Gen Pract. 2011:61(584):197-9.

9. McBride ML, Lorenzi MF, Page J, Broemeling AM, Spinelli JJ, Goddard K, Pritchard S, Rogers P, Sheps S. Patterns of physician follow-up among young cancer survivors: report of the Childhood, Adolescent, and Young Adult Cancer Survivors (CAYACS) research program. Can Fam Physician. 2011;57(12):e482-90.

10. Oeffinger KC, Mertens AC, Hudson MM, Gurney JG, Casillas J, Chen H, Whitton J, Yeazel M, Yasui Y, Robison LL. Health care of young adult survivors of childhood cancer: a report from the Childhood Cancer Survivor Study. Ann Fam Med. 2004;2(1):61-70.

11. Shaw AK, Pogany L, Speechley KN, Maunsell E, Barrera M, Mery LS. Use of health care services by survivors of childhood and adolescent cancer in Canada. Cancer. 2006;106(8):1829-37.

12. McBride ML, Rogers PC, Sheps SB, Glickman V, Broemeling AM, Goddard K Hu J, Lorenzi M, Peacock S, Pritchard S, et al. Childhood, adolescent, and young adult cancer survivors research program of British Columbia: objectives, study design, and cohort characteristics. Pediatr Blood Cancer. 2010:55(2):324-30.

13. World Health Organization. International classification of diseases and health related problems. Geneva: World Health Organization; 1992.

14. Lawless JF. Negative binomial and mixed Poisson regression. Can J Stat. 1987;15(3):209-25 